\title{
Examination on factors affecting symptom change after drug withdrawal in patients with erosive gastroesophageal reflux disease undergoing symptom-controlled maintenance therapy with acid- secretion inhibition drugs
}

\section{Hironori Tanaka}

Osaka Medical and Pharmaceutical University

Toshihisa Takeuchi ( $\nabla$ toshihisa.takeuchi@ompu.ac.jp )

Osaka Medical and Pharmaceutical University Hospital

\section{Shinya Nishida}

Osaka Medical and Pharmaceutical University Hospital

Hitosi Hongo

Fujita Gastroenterological Hospital

Michiaki Takii

Osaka Medical and Pharmaceutical University Mishima-Minami Hospital

Takeshi Higashino

Shiroyama Hospital

Makoto Sanomura

Hokusetsu General Hospital

Hirota Miyazaki

Hanwasumiyoshi General Hospital

Masahiro Hoshimoto

Seikeikai Hospital

\section{Tsuguhiro Kimura}

Fujita Gastroenterological Hospital

Masahiro Sakaguchi

Moriguchi Keijinkai Hospital

\section{Takashi Abe}

Hanwasumiyoshi General Hospital

\section{Akitoshi Hakoda}

Osaka Medical and Pharmaceutical University

Noriaki Sugawara

Osaka Medical and Pharmaceutical University 


\section{Taro Iwatsubo}

Osaka Medical and Pharmaceutical University

\section{Shinpei Kawaguchi}

Osaka Medical and Pharmaceutical University

\section{Kazuhiro Ota}

Osaka Medical and Pharmaceutical University

\section{Yuichi Kojima}

Osaka Medical and Pharmaceutical University Hospital

\section{Kazuhide Higuchi}

Osaka Medical and Pharmaceutical University

\section{Research Article}

Keywords: GERD, rebound, proton pump inhibitor, vonoprazan

Posted Date: February 10th, 2022

DOI: https://doi.org/10.21203/rs.3.rs-1329576/v1

License: (c) (i) This work is licensed under a Creative Commons Attribution 4.0 International License. Read Full License 


\section{Abstract}

Background: In patients with gastroesophageal reflux disease (GERD) on maintenance therapy with acidsuppressive drugs, it is not clear what background factors allow patients to discontinue the drugs. The aim is to examine the relationship of the changes in the frequency and severity of gastrointestinal symptoms after discontinuation of acid-secretion inhibitors for erosive GERD (eGERD) with possible patient background factors, and to identify factors that influence these changes.

Methods: This is a multicenter, open-label, interventional, exploratory study. eGERD patients with mild mucosal injury whose symptoms were under control and who were on maintenance therapy with acidsuppressive drugs were withdrawn from the drug treatment for 4 weeks. We examined the relationship of patient background (sex, age, body mass index, alcohol consumption, smoking habits), esophageal hiatal hernia, H. pylori infection, pepsinogen I and II concentrations and I/II ratios, blood gastrin levels before and after drug discontinuation with total score change in Frequency Scale for the symptoms of GERD (FSSG) .

Results: Of the 92 patients whose symptoms could be assessed before and after drug withdrawal, 66 patients ( $71.7 \%$ of the total) had FSSG $<8$ and no symptom relapse after withdrawal. Furthermore, patient background factors that may be related to symptom relapse/non-relapse were examined, but no related factors were detected. The maintenance medications before discontinuation in the above 92 patients were a proton pump inhibitor (PPI) and vonoprazan (VPZ, a potassium ion competitive acid blocker). Since both drugs were administered to about the same number of patients though incidentally, we examined the relationship between patient background factors and symptom relapse/non-relapse by treatment group. As a result, no relevant background factors were detected in both groups. Although there were no significant differences between the two groups, the severity and frequency of symptom recurrence in the VPZ group tended to be higher than in the PPI group.

Conclusions: Consideration of background factors is unlikely to be required in the discontinuation of maintenance therapy for eGERD. There was no significant difference in the extent of disease or frequency of recurrence during the discontinuation period, regardless of whether the drug before discontinuation was a PPI or VPZ.

Trial registration: The study was registered in the UMIN Clinical Trial Registry (UMIN000029957).

\section{Background}

Gastroesophageal reflux disease (GERD) is a disease with an extremely high recurrence rate and requires long-term management even the symptoms are mild [1, 2-7]. Proton pump inhibitors (PPIs) or vonoprazan (VPZ), a potassium-competitive acid blocker (P-CAB) with a stronger effect than PPIs, are the first choice for medication of GERD in Japan [1]. The following clinical issues have been identified for PPIs: (1) the onset of effects takes several days after administration [8, 9], (2) cytochrome P450s including CYP2C19 are involved in the metabolism resulting in individual differences due to genetic polymorphisms [10-12], 
(3) obtaining an inhibitory effect on acid secretion at night is difficult [13], and (4) PPIs are unstable under acidic conditions [14]. On the other hand, VPZ has been reported to almost overcome these issues [13-17], and was introduced in Japan in February 2015 [2].

When symptoms are once improved by the initial treatment with acid-secretion inhibition drugs (ASIDs), the maintenance, intermittent, on-demand, and step-down therapies are used to prevent recurrence by administering the lowest necessary dose of ASIDs in the subsequent long-term management and are recommended in the Japanese Guidelines for the Treatment of GERD 2015 [18], 2021 [1], and the US Guidelines [19]. The reasons for keeping acid suppression to the lowest necessary dose include avoiding the risk of side effects including neuroendocrine tumors [20-23] and Clostridioides difficile infection [24] associated with hypergastrinemia, which are concerns about long-term acid suppression, and costeffectiveness [25]. Rapid increase in gastric acid secretion is involved in the relapse of GERD symptoms after discontinuation of ASIDs, and it is reported that the larger the change in blood gastrin level before and after discontinuation, the more likely rebound occurs [26]. Thus, when considering the discontinuation of ASIDs in the maintenance treatment of GERD, it is important to maintain blood gastrin levels as low as possible before discontinuation and keep acid-suppressive therapy to the minimum necessary.

There are, however, questions about common factors in GERD patients who can discontinue ASIDs and about factors affecting the duration of discontinuation. Furthermore, there are no detailed reports on symptom recurrence after the discontinuation of maintenance therapy with VPZ.

In this study, we exploratively investigated factors associated with the change and incidence of symptoms after drug discontinuation in erosive GERD (eGERD) patients whose symptoms were controlled by maintenance therapy with ASIDs.

\section{Subjects And Methods}

Study design: This is a multicenter, open-label, interventional, exploratory study to determine the frequency and severity of recurrence of gastrointestinal symptoms after discontinuation of ASIDs for eGERD and to explore factors that may influence the symptoms. The Gastrointestinal Endoscopy Center at Osaka Medical and Pharmaceutical University Hospital lead to this study from November 2017 to November 2020. The ethics committee of each institution reviewed the protocol. Upon obtaining permission, the study was conducted in accordance with the Declaration of Helsinki and the Japanese Guidance on Clinical Trials, and the subjects were fully informed about the study in advance and provided written informed consent.

Subjects: The inclusion criteria were: (1) GERD patients diagnosed as grade A/B minor mucosal injury by Los Angeles (LA) classification on upper gastrointestinal endoscopy, (2) patients treated with ASIDs at maintenance doses for $\geq 1$ month, and (3) patients whose symptoms had improved to a total score of $<8$ in the subsequent retrospective questions on a patient self-completion questionnaire for the Frequency Scale for the Symptoms of GERD (FSSG). 
The exclusion criteria were: subjects with severe mucosal injury of grade C/D in the LA classification, considering serious complications (bleeding and stenosis) associated with discontinuation of ASIDs.

Case setting: Based on a previous report [4], the incidence of symptoms after 4 weeks without treatment was assumed to be $40 \%$. The number of target patients was set to 150 for which the $95 \%$ confidence interval of the incidence rate could be obtained with a precision of within $\pm 10 \%$ (significance level $5 \%$ on both sides).

Methods: The treatment with ASIDs was stopped for the included patients. Based on a previous report [27], the observation period after discontinuation was set at 4 weeks.

Blood pepsinogen I and II levels including I/II ratio and blood $H$. pylori antibodies were measured at the time of withdrawal, and blood gastrin levels were measured at the initiation of withdrawal and Week 4 after withdrawal. The subjects were handed sheets of FSSG, Gastrointestinal Symptom Rating Scale (GSRS), and Hospital Anxiety and Depression Scale (HADS) at the withdrawal, and asked to complete the sheets at the initiation of withdrawal and Weeks $1,2,3$, and 4 . The symptom questionnaires were collected at the visit after Week 4. The survey items in the questionnaires and case reports are those described in Table 1 in addition to types/dosage of ASIDs, gastrointestinal drugs other than ASIDs, concomitant drugs, antiplatelet drugs excluding low-dose aspirin, anticoagulants, steroids, and bisphosphonates.

The intake of drugs including gastroprokinetic agents and antagonists of PPI, P-CAB, and $\mathrm{H}_{2}$-receptor affecting the study results were prohibited.

Evaluation and statistical analysis: We examined the association of the variation in FSSG total score with items given in Table 1 (primary endpoint).

Secondary endpoints were to examine the variations in the scores of GSRS, FSSG (reflux, dyskinesia), and HADS (depression) including subscales and factors affecting the variations.

Regarding the statistical methods employed, frequencies and percentages of background factors were presented as nominal and ordinal scales, and summary statistics were calculated for continuous quantities. Unpaired t-test and Fisher's exact probability test were performed according to the nature of the data. Each endpoint on Day 1 and at each measurement time point was analyzed using a paired ttest, while single regression analysis was used for the change in FSSG and GSRS scores. Hypothesis tests were two-tailed, and the significance level was set at $5 \%$ without considering multiplicity because the purpose was exploratory evaluation. SAS 9.4 (SAS Institute Inc., Cary, NC, USA) was used for all analyses.

\section{Results}


When setting up the study, the target number of enrolled patients was set at 150, but in reality, the planned number of patients was unable to be collected within the study period; thus, totaling 99 patients were enrolled. Of these, 93 subjects for whom FSSG scores on Day 1 were available were included in the analyses.

Patient background: Table 1 summarizes the summary statistics (mean \pm SD) on Day 1 for the background factors and treatment factors that may affect eGERD treatment and shows the values for the entire patient population and for the respective PPI and VPZ groups, though the primary endpoint targeted the entire population only. Of the included 93 patients, male and female were respectively 55 (59.1\%) and 38 (40.9\%), without significant difference. Seventy subjects (75.3\% of the total) were over 60 years of age. The drugs administered were either PPIs (esomeprazole: 27 cases, omeprazole: 1 case, rabeprazole: 15 cases, lansoprazole: 4 cases) or VPZ.

Although it was not initially set as an endpoint, since almost the same number of patients $(\mathrm{N}=45-47)$ were included in each PPI and VPZ group, we deviated from protocol to conduct inter-group comparison, and in Table 1 gives the data for the respective groups. The results show that there were statistically significant inter-group differences $(\mathrm{p}<0.05)$ for sex, BMI, blood gastrin levels, blood pepsinogen I, II levels, I/II ratios, and LA classification A/B, but no inter-group differences in other parameters.

\section{Symptom relapse after drug withdrawal, non-relapse factors, and change in blood gastrin}

level: Mean $\pm S D$ of summary statistics at Week 4 for the same items as in Table 1 is shown for entire population and the patients stratified by FSSG $<8$ (non-relapse) and FSSG $\geq 8$ (relapse) (Table 2).

Although symptoms of 92 patients could be assessed just before and after the withdrawal, since there were some subjects missing some data for the items on Day 1 or Week 4, the evaluation of variations could be performed in 91 cases. Of the 91 patients, 66 (72.5\%) had FSSG <8 after withdrawal.

There was no statistically significant difference $(p<0.05)$ between the patients with $F S S G<8$ and FSSG $\geq$ 8 in any of the items examined, and there was no association of symptom relapse with any of the factors.

Table 3 shows the respective blood gastrin levels and variations from Day 1 to Week 4 for entire population and each group. The amount of variation was significantly lower at Week 4 . Since there was already a significant inter-group difference on Day 1, we performed a covariance analysis using the Day 1 values as covariates; the inter-group difference was statistically insignificant at $p=0.808$ (Table 4).

Symptom transition after drug suspension: Table 5 shows the FSSG total scores at Day 1 and each Week for entire population and the patients in the two groups. The total scores at each Week were higher than those on Day 1 with statistical significance $(p<0.001)$ in the two dose groups and entire population. Comparison of the two groups for the variations in FSSG total scores at each time point (unpaired t-test) demonstrates that the VPZ group was higher than the PPI group, though without statistical significance (Fig. 1). The results of the subscores by acid reflux-related symptom and motor deficiency symptom are 
shown in Tables 6 and 7, respectively. The comparison of the amount of variation in the FSSG subscores at each time point shows an increasing trend over time without significant difference, and the comparison of the two groups (unpaired t-test) shows no significant difference. However, all the subscores were higher in the VPZ group than those in the PPI group at each time point (Figs 2 and 3 ).

Next, we examined the GSRS total scores/subscores and the HADS scores; between Day 1 and each time point, there was no significant difference in the amount of variations in the HADS scores but the difference in the GSRS total score was significant at $p<0.001$. There were also significant differences in the subscales of acid reflux and abdominal pain. Indigestion, diarrhea, and constipation, however, show no significant difference (See Table 1 in Supplementary file).

The percentage of subjects with FSSG total score of $\geq 8$ in the two groups and entire population was calculated using the number of subjects on Day 1 as the denominator (Fig. 4). To assess whether the distribution of FSSG total score $(<8 / \geq 8)$ at each time point differed among the ASIDs, we compared it by Fisher's exact probability test. As a result, no statistically significant difference was obtained at any time points. The number of subjects in the VPZ group with FSSG total score of $\geq 8$, however, remained around $30 \%$ except for $39.1 \%$ at Week 3 . In the PPI group, the number of subjects with FSSG total score of $\geq 8$ showed an upward tendency over time from approximately $15 \%$ to $21 \%$ except for $27.7 \%$ at Week 4 .

A single regression analysis was performed with the amount of variations in FSSG total scores at Week 4 as the objective variable and the background factors of continuous volume (age, BMI, blood gastrin levels, and pepsinogen $\mathrm{I} / \mathrm{II}$ ratios at enrollment) and questionnaire results at the enrollment (total scores of FSSG, GSRS, and HADS) as explanatory variables. No statistically significant correlations were observed for any of the factors, and for the FSSG subscores. Single regression analysis of the variations in GSRS subscores at Week 4 shows weak correlations with BMI of 0.2562 for the acid reflux subscore, Day 1 blood gastrin level of 0.2081 for abdominal pain, and age of 0.2874 for the constipation score (See Table 2 of Supplementary file).

\section{Discussion}

The above results demonstrate that we could suspend the ASIDs for at least 4 weeks in nearly $70 \%$ of eGERD patients with mild mucosal injury under control on maintenance therapy with ASIDs.

The primary endpoint of this study was to examine patient background factors affecting drug withdrawal in the entire patient population, but we could not identify such factors in practice. Each patient received either PPIs or VPZ, and approximately equal numbers of patients $(n=45-47)$ were incidentally distributed in the PPI and VPZ groups (Table 1). Therefore, we tried to compare the two groups, although this was not an endpoint set in the protocol. Among the patient backgrounds, statistically significant inter-group differences $(p<0.05)$ were observed for sex, BMI, blood gastrin levels, blood pepsinogen I and II concentrations and I/II ratios, and LA classification A /B. The higher blood gastrin levels in the VPZ group may be attributable to the higher inhibitory effect of VPZ on acid secretion than PPIs. Similar results are 
reported in several papers [28-30]. The reason why blood pepsinogen I/II concentrations were higher in the VPZ-treated group may be attributable to the high acid-secretion inhibition effect of VPZ.

It is interesting to note that blood gastrin levels (Table 1), FSSG total scores (Table 5), and FSSG subscores (Tables 6,7 ) were tended to be higher in the VPZ group than those in the PPI group on Day 1 and Week 4.

The following factors, which are likely to affect symptoms after the drug withdrawal, were examined: patient background items listed in Table 1; total score and subscores of FSSG, HADS, and GSRS; and other gastrointestinal drugs and concomitant medications in use. No correlative factors were found except for BMI exhibiting a weak correlation with the acid-reflux related GSRS subscore, and age exhibiting a weak correlation with the constipation score. The FSSG was additionally stratified into $\geq 8$ and $<8$ to examine factors correlated with disease status, but no correlative factors were found (Table 2). This result may be attributable to the smaller number of patients, but there is possibility that the factors examined do not have a strong association with GERD relapse during withdrawal. Thus, patients with certain backgrounds are not more prone to relapse; suggesting that there is little need to take the patient backgrounds into account in drug discontinuation.

There was no statistically significant inter-group difference in symptom recurrence after drug withdrawal, but there was a tendency toward a higher frequency of recurrence in the VPZ group at each week. In the VPZ group, the FSSG total score of $\geq 8$ was around $30 \%$ at each time point, whereas in the PPI group it was from $15 \%$ to $21 \%$ (Fig. 4). This tendency toward a high relapse incidence in the VPZ group is consistent with the greater change in blood gastrin levels in this group.

The review by the American Gastroenterological Association [31] describes that PPIs have little causality with adverse events including renal impairment, dementia. We previously reported that the effect of VPZ is considerably stronger than the rabeprazole belonging to PPIs; VPZ maintained a high pH even at doses as low as 1/2-1/4 times the standard dose of rabeprazole. Therefore, VPZ caused significantly higher blood gastrin levels. This is consistent with the result that VPZ had shorter blood half-life of $7.7 \mathrm{hr}$ than that in the stomach where VPZ remains as unchanged drug for a longer time because it was inactivated by acid [32]. There are no reports on serious side effects of VPZ for up to two years [33], but elucidation of the safety of VPZ in long-term maintenance therapy is important. This study show that there was no significant inter-group difference $(p<0.05)$ in most of the patient background factors on Day 1 , except for blood gastrin level, pepsinogen levels and I/II ratios, and LA classification. Among these, blood gastrin levels were significantly higher in the VPZ group $(383.3 \pm 281.7 \mathrm{pg} / \mathrm{mL})$ than those in the PPI group $(800.3 \pm 603.5 \mathrm{pg} / \mathrm{mL}$ : the finding being consistent with the description in the above report [30].

There is a report [34] affirming the acid hypersecretion by ASID discontinuation, but several articles [3537] reporting that this is not a major problem. We have, however, thought that the possibility of acid hypersecretion is important in discontinuation of drugs with strong efficacy. 
If the goal is to wean patients from ASID in the treatment of GERD, it is important to keep in mind the side effects that may occur during the maintenance therapy and the need to avoid rebound after discontinuation. From these points of view, the maintenance therapy for GERD should avoid unnecessarily prolonged strong acid-secretion suppression, even if symptoms are improving.

There are several limitations to this study: (1) the number of subjects was smaller than originally planned, (2) the drug withdrawal period was 4 weeks, and (3) endoscopy was not performed after the drug withdrawal.

\section{Conclusion}

There were no patient factors to be considered in the discontinuation of maintenance therapy for eGERD. There was no significant difference in the extent of disease or frequency of recurrence during the discontinuation period, regardless of whether the drug before discontinuation was PPIs or VPZ. Since $70 \%$ of patients did not experience recurrence for at least 4 weeks and there were no serious complications even in patients experiencing recurrence, temporary discontinuation of maintenance therapy with ASIDs, especially with PPIs, is acceptable for mild eGERD.

\section{Abbreviations}

\begin{tabular}{|ll|}
\hline Abbreviation & Meaning of abbreviation \\
\hline ASID & Acid-secretion inhibition drug \\
\hline BMI & Body mass index \\
\hline CYP & Cytochrome P450 \\
\hline FSSG & Frequency scale for the symptoms of gastroesophageal reflux disease (GERD) \\
\hline GERD & Erosive gastroesophageal reflux disease \\
\hline GSRS & Gastroesophageal reflux disease \\
\hline HADS & Hospital anxiety and depression scale \\
\hline LA & Los Angels \\
\hline P-CAB & Potassium-competitive acid blocker \\
\hline PPI & Proton pump inhibitor \\
\hline VPZ & Vonoprazan \\
\hline
\end{tabular}

\section{Declarations}




\section{Ethics approval and consent to participate}

This study was approved by the ethics committees of each institution for human research, based on the Declaration of Helsinki and the Japanese Guidance on Clinical Trials.

\section{Consent for publication}

Not applicable.

\section{Availability of data and materials}

The datasets during and/or analyzed during this study are available from the corresponding author on reasonable request.

\section{Competing interests}

All authors declare that they have no competing interests.

\section{Funding}

This research was financially supported with an Investigator Sponsored Study Program of AstraZeneca Co. Ltd., Japan.

\section{Authors' contributions}

Takeuchi T: Preparation, reviewing, and edition of this paper, performing data curation and formal analysis, and supervising methodology and visualization. Tanaka H, Nishida S, Hongo H, Takii M, Higashino T, Sanomura M, Miyazaki H, Hoshimoto M, Kimura T, Sakaguchi M, Abe T, Hakoda A, Sugawara N, Iwatsubo T, Kawaguchi S, Ota K and Kojima Y: Investigation, Resources. Higuchi $\mathrm{K}$ : Preparation, reviewing, and edition of this paper, Study supervision.

\section{Acknowledgements}

We thank MC\&P Co. Ltd., Tokyo, Japan for the technical assistance in data management, statistical analysis, and English language editing service.

\section{References}

1. Iwakiri K. Fujiwara Y. Akiyama J, lijima K, Ishimura N, Ihara E, et al. Evidence-based Clinical Practice Guidelines for Gstroesophageal Reflux Disease (GERD) 2020 (3rd Edition). Ed. by The J Soc Gastroenterol.

2. Oshima T, Miwa H. Potent Potassium-competitive Acid Blockers: A New Era for the Treatment of Acid-related Disease. J Neurogastroent Motil 2018; 24: 334-344. 
3. Schindlbeck NE, Klauser AG, Berghammer G, Londong W, Müller-Lissner SA. Three year follow up of patients with gastrooesophageal reflux disease. Gut 1992; 33: 1016-1019.

4. Carlsson R, Dent J, Watts R, Riley S, Sheikh R, Hatlebakk j, et al. Gastro-oesophageal reflux disease in primary care: an international study of different treatment strategies with omeprazole. International GORD Study Group. Eur. J. Gastroenterol Hepatol. 1998; 10(2), 119-124.

5. Katz PO, Gerson LB, Vela MF. Guidelines for the diagnosis and management of gastroesophageal reflux disease. Am J Gastroentero/ 2013; 108: 308-328; quiz 329.

6. Shey R, Alla SP, Midani D, Parkman HP. Gastroesophageal reflux disease-related symptom recurrence in patients discontinuing proton pump inhibitors for Bravo ${ }^{\circledR}$ wireless esophageal $\mathrm{pH}$ monitoring study. Rev Gastroenterol Mex. 2017 Oct - Dec; 82(4):277-286.

7. Ley WY, Chang WC, Wen SH, Yi CH, Liu TT, Hung JS, et al. Predicting factors of recurrence in patients with gastroesophageal reflux disease: a prospective follow-up analysis. Therap Adv Gastroenterol. 2019; 12:1-11. DOI. 101177/1756284819864549.

8. Cederberg C, Lind T, Röhss K, Olbe L. Comparison of once-daily intravenous and oral omeprazole on pentagastrin-stimulated acid secretion in duodenal ulcer patients. Digestion, 1992; 53, 171-178.

9. Dammann HG. Burkhardt F. Pantoprazole versus omeprazole: influence on meal-stimulated gastric acid secretion. Eur J Gastroenterol Hepatol. 1999; 11:1277-1282.

10. Chong E, Ensom MH. Pharmacogenetics of the proton pump inhibitors: a systematic review. Pharmacotherapy. 2003; 23:460-471.

11. Furuta T, Shirai N, Sugimoto M, Nakamura A, Hishida A, Ishizaki T. Influence of CYP2C19 pharmacogenetic polymorphism on proton pump inhibitor-based therapies. Drug Metab Pharmacokinet. 2005; 20:153-167.

12. Shin JM, Kim N. Pharmacokinetics and pharmacodynamics of the proton pump inhibitors. J Neurogastroenterol Motil. 2013; 19:25-35.

13. Sakurai Y, Mori Y, Okamoto H, Nishimura A, Komura E, Araki T, et al. Acid-inhibitory effects of vonoprazan $20 \mathrm{mg}$ compared with esomeprazole $20 \mathrm{mg}$ or rabeprazole $10 \mathrm{mg}$ in healthy adult male subjects-a randomised open-label cross-over study. Aliment Pharmacol Ther. 2015; 42:719-730.

14. Otake K, Sakurai Y, Nishida H, Fukui H, Tagawa Y, Yamasaki H, et al. Characteristics of the novel potassium-competitive acid blocker vonoprazan fumarate (TAK-438). Adv Ther. 2016; 33:1140-1157.

15. Andersson K, Carlsson E. Potassium-competitive acid blockade: a new therapeutic strategy in acidrelated diseases. Pharmacol Ther. 2005; 108:294-307.

16. Sakurai Y, Mori Y, Okamoto H, Nishimura A, Komura E, Araki T, et al. Acid-inhibitory effects of vonoprazan $20 \mathrm{mg}$ compared with esomeprazole $20 \mathrm{mg}$ or rabeprazole $10 \mathrm{mg}$ in healthy adult male subjects - a randomised open-label cross-over study. Aliment Pharmacol Ther. 2015; 42:719-730.

17. Ashida K, Sakurai Y, Nishimura A, Kudou K, Hiramatsu A, Umegaki E, et al. Randomised clinical trial: a dose-ranging study pf vonoprazan, a novel potassium-competitive acid blocker, vs. lansoprazole for the treatment of erosive oesophagitis. Aliment Pharmacol Ther. 2015; 42:685-695. 
18. Kinoshita Y, Iwakiri K, Ashida K, Iwakiri R, Oshima T, Ohara S, et al. Evidence-based Clinical Practice Guidelines for GERD 2015 (2nd Edition). Ed. by The J Soc Gastroenterol. J Gastroenterol 2016; 51:751-767.

19. DeVault KR, Castell DO: Updated guidelines for the diagnosis and treatment of gastroesophageal reflux disease. Am J Gastroenterol. 2005, 100; 190-200.

20. Anjiki H, Mukaisho K, Kadomoto Y, Doi H, Yoshikawa K, Nakayama T, et al. Adenocarcinoma arising in multiple hyperplastic polyps in a patient with Helicobacter pylori infection and hypergastrinaemia during long-term proton pump inhibitor therapy. Clin J Gastroenterol. 2017;10:128-136.

21. Jianu CS, Lange OJ, Viset T, Ovigstad G, Martinsen TC, Fougner R, et al. Gastric neuroendocrine carcinoma after long-term use of proton pump inhibitor. Scand J Gastroenterol. 2012;47:64-67.

22. Jianu CS, Fossmark R, Viset T, Ovigstad G, SØrdal O, Mårvik R, et al. Gastric carcinoids after longterm use of a proton pump inhibitor. Aliment Pharmacol Ther. 2012;36:644-649.

23. Nandy N, Hanson JA, Strickland RG, McCarthy DM. Solitary Gastric Carcinoid Tumor Associated with Long-Term Use of Omeprazole: A Case Report and Review of the Literature. Dig Dis Sci. 2016;61:708712.

24. Moayyedi P, Eikelboom JW, Bosh J, Connolly SJ, Dyal L, Shestakovska O, et al. Safety of Proton Pump Inhibitors Based on a Large, Multi-Year, Randomized Trial of Patients Receiving Rivaroxaban or Aspirin. Gastroenterology. 2019;157(3):682-691.

25. Hosaka H: GERD + NERD Diagnosis, Q \& A. 2011, pp 113-116, Ed. by Kusano M, 2011, Nihon lji Shinposha.

26. Hosaka H: GERD + NERD Diagnosis, Q \& A. 2011, pp 122-127, Ed. by Kusano M, Nihon lji Shimposha.

27. Niklasson A, Lindstőm L, Simrèn M, Lindberg G, Bjőrnsson E. Dyspeptic Symptom development after discontinuation of a proton pump inhibitor; a double blind placebo-controlled trial. Am J Gastroenterol, 2010, 105: 1531-1537.

28. Jenkins H, Sakurai Y, Nishimura A, Okamoto H, Hibberd M, Jenkins R, et al: Randomised clinical trial: safety, tolerability, pharmacokinetic, and pharmacodynamics of repeated doses of TAK-438 (vonoprazan), a novel potassium-competitive acid blocker, in healthy subjects. Alimental Pharmacol Ther $2015 ; 41: 636-648$.

29. Ashida K, Sakurai Y, Nishimura A, Kudou K, Hiramatsu N, Umegaki E, et al: Randomised clinical trial: a dose-ranging study of vonoprazan, a novel potassium-competitive acid blocker, vs. lansoprazole for the treatment of erosive oesophagitis. Alimental Pharmacol Ther 2015; 42:685-695.

30. Akiyama J, Hosaka H, Kuribayashi S, Moriyasu S, Hisada Y, Okubo H, et al: Efficacy of Vonoprazan, a Novel Potassium-Competitive Acid Blocker, in Patients with Proton Pump Inhibitor-Refractory Acid Reflux. Digestion 2020; 101:174-183.

31. Daniel EF, Lawrence SK, Yu-Xiao Y. The Risks and Benefits of Long-term Use of Proton Pump Inhibitors: Expert Review and Best Practice Advice from the American Gastroenterological Association. Gastroenterology. 2017;152(4):706-715. 
32. Takeuchi T, Furuta T, Fujiwara Y $\square$ Sugimoto $M$, Kasugai $K$, Kusano M, et al: Randomized trial of acid inhibition by vonoprazan $10 / 20 \mathrm{mg}$ once daily vs rabeprazole $10 / 20 \mathrm{mg}$ twice daily in healthy Japanese volunteers (SAMURAI pH study). Aliment Pharmac Therap 2020; 51:534-543.

33. Kawai T, Oda K, Funao N₫Nishimura A, Matsumoto Y, Mizokami Y, et al. Vonoprazan prevents lowdose aspirin-associated ulcer recurrence: randomized phase 3 study. Gut 2018; 67:1033-1041.

34. Reimer C, Søndergaard B, Hilsted L, Bytzer P. Proton-pump inhibitor therapy induces acid-related symptoms in healthy volunteers after withdrawal of therapy. Gastroenterol 2009;137(1):80-87, 87.

35. Peura D, Le Moigne A, Pollack C, Nagy P, Lind T. A 14-day regimen of esomeprazole $20 \mathrm{mg} /$ day for frequent heartburn: durability of effects, symptomatic rebound, and treatment satisfaction. Postgrad Med 2016;128(6);577-583.

36. Metz DC, Pilmer BL, Han C, Peretz MC. Withdrawing PPI therapy after healing esophagitis does not worsen symptoms or cause persistent hypergastrinemia: Analysis of dexlansoprazole MR clinical trial data. Am J Gastroenterol 2011;106(11):1953-1960.

37. Juul-Hansen P, Rydning A. Clinical and pathophysiological consequences of on-demand treatment with PPI in endoscopy-negative reflux disease. Is rebound hypersecretion of acid a problem? Scand J Gastroenterol 2011;46(4):398-405.

\section{Tables}

Table 1 Patient background and treatment on Day 1 by conventional PPI and VPZ dose groups 


\begin{tabular}{|c|c|c|c|c|}
\hline Factor & Item & Mean \pm SD & Min-Med-Max & $P$ value \\
\hline \multirow{27}{*}{$\begin{array}{l}\text { Patient } \\
\text { background }\end{array}$} & Sex: male (\%)/female (\%) & \multicolumn{2}{|l|}{ No. of subjects } & $0.036^{a}$ \\
\hline & Entire population $(\mathrm{n}=93)$ & \multicolumn{2}{|c|}{$55(59.1 \%) / 38(40.9 \%)$} & \\
\hline & PPI $(n=47)$ & \multicolumn{2}{|c|}{33 (70.2\%)/14 (29.8\%) } & \\
\hline & VPZ $(n=46)$ & \multicolumn{2}{|c|}{$22(47.8 \%) / 24(52.2 \%)$} & \\
\hline & Age (year) & $64.8 \pm 13.7$ & $25.0-68.0-93.0$ & $0.067^{b}$ \\
\hline & Entire population $(n=93)$ & $67.4 \pm 11.4$ & $40.0-70.0-93.0$ & \\
\hline & PPI $(n=47)$ & \multirow[t]{2}{*}{$62.2 \pm 15.4$} & \multirow[t]{2}{*}{$25.0-68.0-79.0$} & \\
\hline & VPZ $(n=46)$ & & & \\
\hline & Height $(\mathrm{cm})$ & \multirow{2}{*}{$\begin{array}{l}161.78 \pm 9.04 \\
163.30 \pm 9.03\end{array}$} & 140.00-162.00- & \multirow[t]{4}{*}{$0.103^{b}$} \\
\hline & Entire population $(n=93)$ & & 103.00 & \\
\hline & PPI $(n=47)$ & \multirow[t]{2}{*}{$160.24 \pm 8.88$} & $\begin{array}{l}145.00-163.50- \\
180.00\end{array}$ & \\
\hline & VPZ $(n=46)$ & & $\begin{array}{l}140.00-160.00- \\
183.00\end{array}$ & \\
\hline & Weight $(\mathrm{kg})$ & $62.94 \pm 11.41$ & $35.20-63.00-106.00$ & $0.598^{b}$ \\
\hline & Entire population $(\mathrm{n}=93)$ & $62.31 \pm 10.49$ & $35.20-63.00-83.00$ & \\
\hline & PPI $(n=47)$ & \multirow[t]{2}{*}{$63.57 \pm 12.37$} & \multirow[t]{2}{*}{$46.30-62.25-106.00$} & \\
\hline & VPZ $(n=46)$ & & & \\
\hline & $\mathrm{BMI}\left(\mathrm{kg} / \mathrm{m}^{2}\right)$ & $23.96 \pm 3.38$ & $16.20-23.80-41.00$ & $0.048^{b}$ \\
\hline & Entire population $(\mathrm{n}=93)$ & $23.28 \pm 2.89$ & $16.20-23.20-29.10$ & \\
\hline & PPI $(n=47)$ & \multirow[t]{2}{*}{$24.66 \pm 3.71$} & \multirow[t]{2}{*}{$19.30-24.45-41.00$} & \\
\hline & VPZ $(n=46)$ & & & \\
\hline & Blood gastrin $(\mathrm{pg} / \mathrm{mL})$ & $587.2 \pm 510.0$ & $10.0-455.0-2500$ & $<0.001^{b}$ \\
\hline & Entire population $(\mathrm{n}=92)$ & $383.3 \pm 281.7$ & $10.0-280.0-1300$ & \\
\hline & PPI $(n=47)$ & \multirow[t]{2}{*}{$800.3 \pm 603.5$} & \multirow[t]{2}{*}{$69.0-620.0-2500$} & \\
\hline & VPZ $(n=45)$ & & & \\
\hline & $\begin{array}{l}\text { Blood pepsinogen I } \\
\text { (ng/mL) }\end{array}$ & \multirow{3}{*}{$\begin{array}{l}173.07 \pm 159.68 \\
127.96 \pm 70.14 \\
220.20 \pm 207.71\end{array}$} & $\begin{array}{l}24.10-135.50- \\
1040.00\end{array}$ & \multirow[t]{3}{*}{$0.005^{b}$} \\
\hline & Entire population $(n=92)$ & & $\begin{array}{l}24.10-120.00- \\
285.00\end{array}$ & \\
\hline & $\begin{array}{l}\operatorname{PPI}(n=47) \\
\operatorname{VPZ}(n=45)\end{array}$ & & $\begin{array}{l}25.30-153.00- \\
1040.00\end{array}$ & \\
\hline
\end{tabular}




\begin{tabular}{|c|c|c|c|}
\hline Blood pepsinogen II & $31.47 \pm 29.76$ & $4.70-22.35-173.00$ & \multirow[t]{5}{*}{$<0.001^{b}$} \\
\hline & $20.84 \pm 10.71$ & $4.70-19.30-52.40$ & \\
\hline 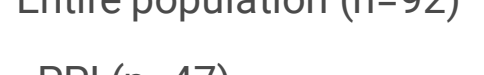 & \multirow[t]{3}{*}{$42.58 \pm 38.27$} & \multirow[t]{3}{*}{$7.30-30.80-173.00$} & \\
\hline $\mathrm{PPI}(\mathrm{n}=47)$ & & & \\
\hline VPZ $(n=45)$ & & & \\
\hline Pepsinogen $\mathrm{I} / \mathrm{II}$ ratio & $5.71 \pm 1.70$ & $1.50-5.60-10.00$ & \multirow[t]{4}{*}{$0.008^{b}$} \\
\hline Entire population $(\mathrm{n}=92)$ & $6.17 \pm 1.84$ & $2.70-6.10-10.00$ & \\
\hline PPI (n=47) & \multirow[t]{2}{*}{$5.24 \pm 1.40$} & \multirow[t]{2}{*}{$1.50-5.40-9.60$} & \\
\hline VPZ $(n=45)$ & & & \\
\hline Smoking habit: Yes/No & \multicolumn{2}{|l|}{ No. of subjects } & $1.000^{\mathrm{a}}$ \\
\hline Entire population $(\mathrm{n}=92)$ & \multicolumn{2}{|c|}{$20(21.7 \%) / 72(78.3 \%)$} & \\
\hline PPI $(n=47)$ & \multicolumn{2}{|c|}{10 (21.3\%)/37 (78.7\%) } & \\
\hline VPZ (n=45) & \multicolumn{2}{|c|}{$10(22.2 \%) / 35(77.8 \%)$} & \\
\hline Alcohol drinking: Yes/No & \multicolumn{2}{|l|}{ No. of subjects } & $0.670^{\mathrm{a}}$ \\
\hline Entire population $(\mathrm{n}=92)$ & \multicolumn{2}{|c|}{$56(60.9 \%) / 36(39.1 \%)$} & \\
\hline PPI $(n=47)$ & \multicolumn{2}{|c|}{$30(63.8 \%) / 17(36.2 \%)$} & \\
\hline VPZ $(n=45)$ & \multicolumn{2}{|c|}{$26(57.8 \%) / 19(42.2 \%)$} & \\
\hline
\end{tabular}

*: Comparison between conventional PPI and VPZ dose groups, ${ }^{a}$ : Fishers' exact probability test, ${ }^{\mathrm{b}}$ : Unpaired t-test, Day 1: starting day of drug discontinuation, GERD: gastroesophageal reflux disease, LA: Los Angeles, Max: maximum, Med: median, Min: minimum, No.: No. of patients, PPI: proton pump inhibitor, SD: Standard deviation, VPZ: vonoprazan

Table 2 Patient background and treatment at Week 4 by group with FSSG $<8$ and group with FSSG $\geq 8$ 


\begin{tabular}{|c|c|c|c|c|}
\hline Factor & Item & Mean \pm SD & Min-Med-Max & $P$ value \\
\hline \multirow{28}{*}{$\begin{array}{l}\text { Patient } \\
\text { background }\end{array}$} & Sex: male (\%)/female (\%) & \multicolumn{2}{|l|}{ No. of subjects } & $0.640^{\mathrm{a}}$ \\
\hline & Entire population $(\mathrm{n}=92)$ & \multicolumn{2}{|c|}{$54(58.7 \%) / 38(58.7 \%)$} & \\
\hline & FSSG<8 $(n=66)$ & \multicolumn{2}{|c|}{$40(60.6 \%) / 26(39.4 \%)$} & \\
\hline & $F S S G \geq 8(n=26)$ & \multicolumn{2}{|c|}{$14(53.8 \%) / 12(46.2 \%)$} & \\
\hline & Age (year) & $64.1 \pm 13.8$ & $25.0-68.0-93.0$ & $0.499^{b}$ \\
\hline & Entire population $(\mathrm{n}=92)$ & \multirow[t]{3}{*}{$66.3 \pm 13.6$} & \multirow[t]{3}{*}{$31.0-70.5-83.0$} & \\
\hline & FSSG<8 $(n=66)$ & & & \\
\hline & $F S S G \geq 8(n=26)$ & & & \\
\hline & Height (cm) & $162.30 \pm 9.72$ & \multirow{2}{*}{$\begin{array}{l}140.00-163.05- \\
183.00\end{array}$} & \multirow[t]{4}{*}{$0.433^{b}$} \\
\hline & Entire population $(\mathrm{n}=92)$ & \multirow[t]{3}{*}{$160.65 \pm 7.19$} & & \\
\hline & FSSG<8 $(n=66)$ & & $\begin{array}{l}14 / .00-160.65- \\
174.00\end{array}$ & \\
\hline & FFSSG $\geq 8(n=26)$ & & & \\
\hline & Weight (kg) & $63.36 \pm 11.97$ & $46.30-62.00-106.00$ & $0.613^{b}$ \\
\hline & Entire population $(\mathrm{n}=92)$ & \multirow[t]{3}{*}{$62.01 \pm 10.24$} & \multirow[t]{3}{*}{$16.20-64.20-29.30$} & \\
\hline & FSSG<8 $(n=66)$ & & & \\
\hline & $F S S G \geq 8(n=25)$ & & & \\
\hline & $\mathrm{BMI}\left(\mathrm{kg} / \mathrm{m}^{2}\right)$ & $23.97 \pm 3.49$ & $18.60-23.70-41.00$ & $0.958^{b}$ \\
\hline & Entire population $(\mathrm{n}=92)$ & \multirow[t]{3}{*}{$23.93 \pm 3.22$} & \multirow[t]{3}{*}{$19.30-24.35-41.00$} & \\
\hline & FSSG<8 $(n=66)$ & & & \\
\hline & $F S S G \geq 8(n=26)$ & & & \\
\hline & Blood gastrin $(\mathrm{pg} / \mathrm{mL})$ & $575.0 \pm 534.6$ & $10.0-430.0-2500.0$ & $0.770^{\mathrm{b}}$ \\
\hline & Entire population $(\mathrm{n}=91)$ & \multirow[t]{3}{*}{$610.5 \pm 457.4$} & \multirow[t]{3}{*}{$83.0-490.0-1600.0$} & \\
\hline & FSSG<8 $(n=66)$ & & & \\
\hline & $F S S G \geq 8(n=25)$ & & & \\
\hline & $\begin{array}{l}\text { Blood pepsinogen I } \\
\text { (ng/mL) }\end{array}$ & \multirow{4}{*}{$\begin{array}{l}174.74 \pm 176.09 \\
169.83 \pm 112.43\end{array}$} & $\begin{array}{l}24.10-135.50- \\
1040.00\end{array}$ & \multirow[t]{4}{*}{$0.897^{b}$} \\
\hline & Entire population $(n=91)$ & & \multirow{3}{*}{$\begin{array}{l}41.70-129.00- \\
555.00\end{array}$} & \\
\hline & FSSG<8 $(n=66)$ & & & \\
\hline & $F S S G \geq 8(n=25)$ & & & \\
\hline
\end{tabular}




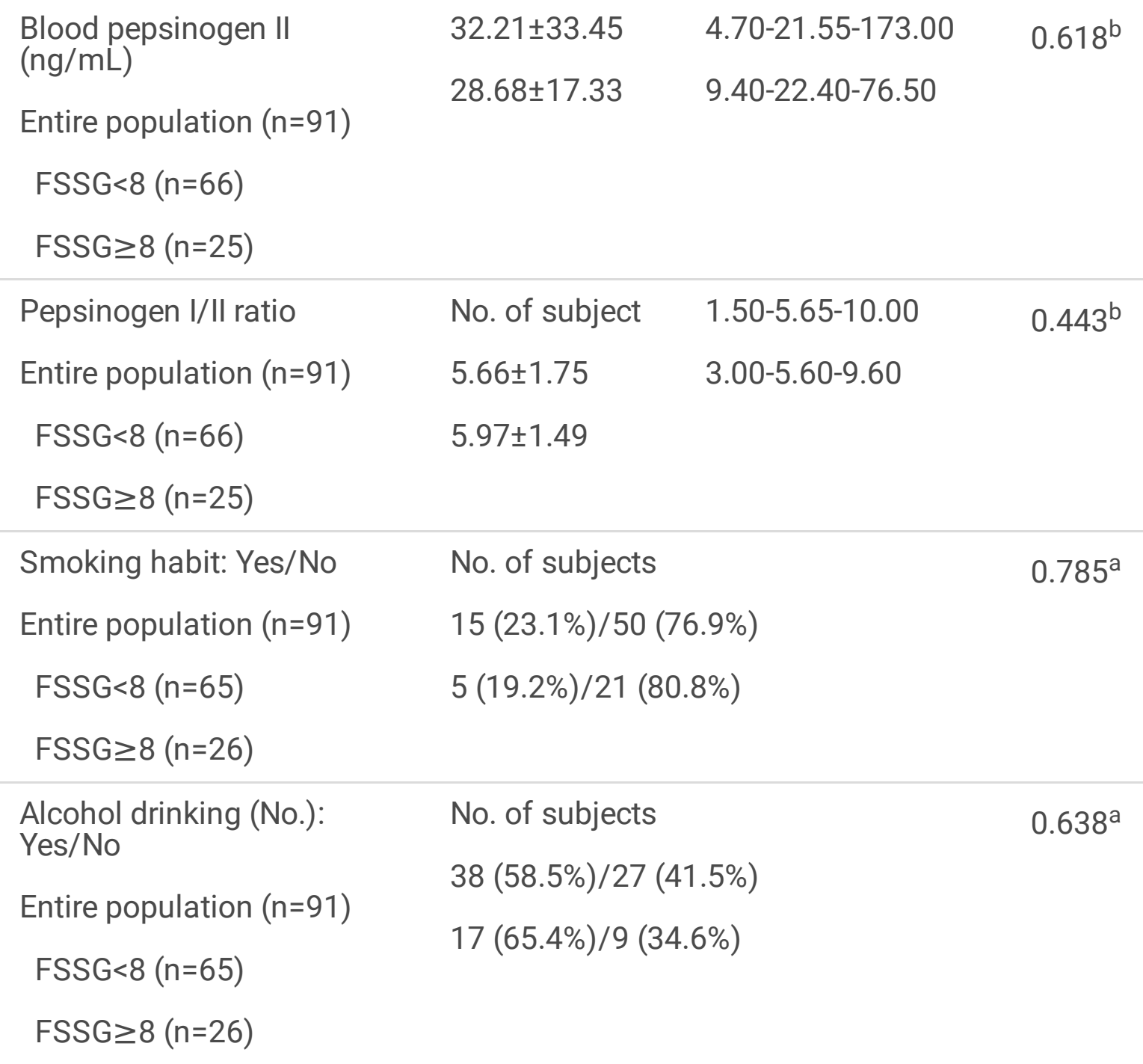

*: Comparison between groups with $F S S G<8$ and FSSG $\geq 8$, a. Fishers' exact probability test, b: Unpaired ttest, BMI: body mass index, FSSG: Frequency Scale for the Symptom of GERD, GERD: gastroesophageal reflux disease, LA: Los Angeles, Max: maximum, Med: median, Min: minimum, No.: No. of patients, SD: Standard deviation, Week 4: At 4 weeks from the starting day of drug withdrawal Table 3 Change of gastrin concentration in blood $(\mathrm{pg} / \mathrm{mL})$ 


\begin{tabular}{|c|c|c|c|c|c|}
\hline & & Day 1 & Week 4 & Variation & $\begin{array}{l}P \\
\text { value* }\end{array}$ \\
\hline \multirow{2}{*}{$\begin{array}{l}\text { Entire } \\
\text { population }^{a}\end{array}$} & Mean \pm SD & $587.2 \pm 510.05$ & $153.97 \pm 197.58$ & $-430.55 \pm 516.26$ & \multirow[t]{2}{*}{$<0.0001$} \\
\hline & $\begin{array}{l}\text { Min-Med- } \\
\text { Max }\end{array}$ & $10-455-2500$ & $10-97.5-1500$ & $-2416--300-500$ & \\
\hline \multirow[t]{2}{*}{ PPI dose group ${ }^{b}$} & Mean \pm SD & $383.26 \pm 281.74$ & $144.54 \pm 172.70$ & $-229.43 \pm 279.74$ & \multirow[t]{2}{*}{$<0.0001$} \\
\hline & $\begin{array}{l}\text { Min-Med- } \\
\text { Max }\end{array}$ & $10-280-1300$ & $10-95.5-970$ & $\begin{array}{l}-1190--176.5- \\
290\end{array}$ & \\
\hline \multirow[t]{2}{*}{ VPZ dose group ${ }^{c}$} & Mean \pm SD & $800.27 \pm 603.48$ & $163.39 \pm 221.22$ & $-636.13 \pm 616.13$ & \multirow[t]{2}{*}{$<0.0001$} \\
\hline & $\begin{array}{l}\text { Min-Med- } \\
\text { Max }\end{array}$ & $69-620-2500$ & 46-99-1500 & $-2416--470-500$ & \\
\hline
\end{tabular}

*: Comparison between Day 1 and Week 4 by using paired t-test, ${ }^{a}: \mathrm{n}=92$ but $\mathrm{n}=91$ for variation because of 1 missing value on Day and at Week4, b: $n=47$ on Day 1 , but $n=46$ at Week 4 and for variation, $\mathrm{c}: \mathrm{n}=45$ on Day 1 and for variation, and $n=46$ at Week 4, Day1: the time of drug withdrawal, Max: maximum, Med: median, Min: minimum, VPZ: Vonoprazan, PPI: proton pump inhibitor, SD: Standard deviation, Week 4: 4 weeks after drug discontinuation, variation: values obtained by subtracting the values on Day 1 from those at Week 4

Table 4 Covariance analysis of variation of blood gastrin between PPI and VPZ dose groups

\begin{tabular}{|llll|}
\hline & Mean least squares & Standard error & $\operatorname{Pr}>|\mathrm{t}|$ \\
\hline PPI dose group & -425.0482 & 30.6515 & $\mathrm{p}<0.001$ \\
\hline VPZ dose group & -436.1729 & 31.0229 & $\mathrm{p}<0.001$ \\
\hline & Mean least squares & $95 \%$ Confidence limit & $\mathrm{Pr}>|\mathrm{t}|$ \\
\hline Difference (PPI - VPZ) & 11.1247 & $-79.6026-101.8519$ & $\mathrm{p}=0.808$ \\
\hline
\end{tabular}

Covariate: variation from Day 1, Day 1: registration time, PPI: proton pump inhibitor, VPZ: vonoprazan, Week 4: Week 4 from the initiation of drug withdrawal

Table 5 Change of FSSG total score 


\begin{tabular}{|c|c|c|c|c|c|}
\hline Observation period & No. of patients & Mean \pm SD & Min-Med-Max & P-value* & P-value** \\
\hline \multicolumn{6}{|c|}{ PPI + VPZ dose groups } \\
\hline Day 1 & 93 & $2.2 \pm 2.3$ & $0-2-7$ & & \\
\hline Week 1 & 93 & $4.8 \pm 5.5$ & $0-3-26$ & $<0.001$ & - \\
\hline Week 2 & 92 & $5.9 \pm 6.4$ & $0-4-28$ & $<0.001$ & - \\
\hline Week 3 & 92 & $6.2 \pm 6.9$ & $0-4-35$ & $<0.001$ & - \\
\hline Week 4 & 92 & $6.3 \pm 7.0$ & $0-5-37$ & $<0.001$ & - \\
\hline \multicolumn{6}{|l|}{ PPI dose group } \\
\hline Day 1 & 47 & $2.0 \pm 2.3$ & $0-1-7$ & & \\
\hline Week 1 & 47 & $3.8 \pm 4.8$ & $0-2-23$ & 0.001 & - \\
\hline Week 2 & 46 & $4.9 \pm 6.3$ & $0-3-28$ & $<0.001$ & - \\
\hline Week 3 & 46 & $5.2 \pm 6.9$ & $0-3.5-35$ & 0.001 & - \\
\hline Week 4 & 46 & $5.3 \pm 6.7$ & $0-3-32$ & $<0.001$ & - \\
\hline \multicolumn{6}{|l|}{ VPZ dose group } \\
\hline Day 1 & 46 & $2.4 \pm 2.3$ & $0-2-7$ & & \\
\hline Week 1 & 46 & $5.7 \pm 6.1$ & $0-2-26$ & $<0.001$ & - \\
\hline Week 2 & 46 & $6.9 \pm 6.3$ & $0-5-23$ & $<0.001$ & - \\
\hline Week 3 & 46 & $7.2 \pm 6.7$ & $0-5-33$ & $<0.001$ & - \\
\hline Week 4 & 46 & $7.2 \pm 7.3$ & $0-5-37$ & $<0.001$ & - \\
\hline \multicolumn{6}{|c|}{ PPI vs. VPZ dose group } \\
\hline \multicolumn{6}{|l|}{ Day 1} \\
\hline Week 1 & & & & - & 0.1060 \\
\hline Week 2 & & & & - & 0.1643 \\
\hline Week 3 & & & & - & 0.2264 \\
\hline Week 4 & & & & - & 0.2522 \\
\hline \multicolumn{6}{|c|}{$\begin{array}{l}\text { *: Comparison of the values at each week with those on Day } 1 \text { determined by paired t-test, } * * \text { : Inter- } \\
\text { group comparison by unpaired t-test, FSSG: Frequency Scale for the Symptom of Gastroesophageal } \\
\text { Reflux Disease, Max: maximum, Med: median, Min: minimum, PPI: proton pump inhibitor, SD: } \\
\text { Standard deviation, VPZ: vonoprazan }\end{array}$} \\
\hline
\end{tabular}

Table 6 Change of FSSG sub-score related to acid reflux 


\begin{tabular}{|c|c|c|c|c|}
\hline Observation period & No. of patients & Mean $\pm S D$ & Min-Med-Max & P-value* \\
\hline \multicolumn{5}{|c|}{ PPI + VPZ dose groups } \\
\hline Day 1 & 92 & $1.0 \pm 1.3$ & $0-0-5$ & \multirow{2}{*}{$\begin{array}{l}<0.001 \\
<0.001\end{array}$} \\
\hline Week 1 & 92 & $2.9 \pm 3.8$ & $0-1.5-20$ & \\
\hline Week 2 & 92 & $3.4 \pm 3.8$ & $0-2-14$ & \multirow{3}{*}{$\begin{array}{l}<0.001 \\
<0.001\end{array}$} \\
\hline Week 3 & 92 & $3.8 \pm 4.3$ & $0-3-20$ & \\
\hline Week 4 & 92 & $3.7 \pm 4.4$ & $0-3-24$ & \\
\hline \multicolumn{5}{|l|}{ PPI dose group } \\
\hline Day 1 & 46 & $1.0 \pm 1.3$ & $0-0-5$ & \\
\hline Week 1 & 46 & $2.2 \pm 3.1$ & $0-1-14$ & $<0.001$ \\
\hline Week 2 & 46 & $2.8 \pm 3.7$ & $0-1-14$ & $<0.001$ \\
\hline Week 3 & 46 & $3.2 \pm 4.2$ & $0-1.5-19$ & $<0.001$ \\
\hline Week 4 & 46 & $3.0 \pm 3.8$ & $0-1-15$ & $<0.001$ \\
\hline \multicolumn{5}{|l|}{ VPZ dose group } \\
\hline Day 1 & 46 & $1.0 \pm 1.3$ & $0-0-4$ & \\
\hline Week 1 & 46 & $3.5 \pm 4.3$ & $0-3-20$ & $<0.001$ \\
\hline Week 2 & 46 & $4.1 \pm 3.9$ & $0-2-14$ & $<0.001$ \\
\hline Week 3 & 46 & $4.5 \pm 4.3$ & $0-3-20$ & $<0.001$ \\
\hline Week 4 & 46 & $4.5 \pm 4.8$ & $0-3-24$ & $<0.001$ \\
\hline \multicolumn{5}{|c|}{$\begin{array}{l}\text { *: Comparison of the values at each week with those on Day } 1 \text { determined by paired t-test, FSSG: } \\
\text { Frequency Scale for the Symptom of Gastroesophageal Reflux Disease, Max: maximum, Med: } \\
\text { median, Min: minimum, PPI: proton pump inhibitor, SD: Standard deviation, VPZ: vonoprazan }\end{array}$} \\
\hline
\end{tabular}




\begin{tabular}{|c|c|c|c|c|}
\hline \multicolumn{5}{|c|}{ Table 7 Change of FSSG sub-score related to dysmotility } \\
\hline Observation period & No. of patients & Mean $\pm S D$ & Min-Med-Max & P-value* \\
\hline \multicolumn{5}{|c|}{ PPI + VPZ dose groups } \\
\hline Day 1 & 93 & $1.2 \pm 1.5$ & $0-1-7$ & \\
\hline Week 1 & 93 & $1.9 \pm 2.2$ & $0-1-9$ & $<0.001$ \\
\hline Week 2 & 92 & $2.5 \pm 2.9$ & $0-1-15$ & $<0.001$ \\
\hline Week 3 & 92 & $2.4 \pm 3.0$ & $0-1-16$ & $<0.001$ \\
\hline Week 4 & 92 & $2.5 \pm 3.1$ & $0-2-17$ & $<0.001$ \\
\hline \multicolumn{5}{|l|}{ PPI dose group } \\
\hline Day 1 & 47 & $1.1 \pm 1.4$ & $0-0-5$ & \\
\hline Week 1 & 47 & $1.6 \pm 2.2$ & $0-1-9$ & 0.022 \\
\hline Week 2 & 46 & $2.1 \pm 3.0$ & $0-1-15$ & 0.004 \\
\hline Week 3 & 46 & $2.0 \pm 3.2$ & $0-1-16$ & 0.021 \\
\hline Week 4 & 46 & $2.3 \pm 3.4$ & $0-1-17$ & 0.009 \\
\hline \multicolumn{5}{|l|}{ VPC dose group } \\
\hline Day 1 & 47 & $1.3 \pm 1.7$ & $0-1-7$ & \\
\hline Week 1 & 47 & $2.2 \pm 2.3$ & $0-2-9$ & 0.002 \\
\hline Week 2 & 46 & $2.8 \pm 2.8$ & $0-2-10$ & $<0.001$ \\
\hline Week 3 & 46 & $2.8 \pm 2.8$ & $0-2-13$ & $<0.001$ \\
\hline Week 4 & 46 & $2.8 \pm 2.8$ & $0-2-13$ & $<0.001$ \\
\hline
\end{tabular}

*: Comparison of the values at each week with those on Day 1 determined by paired t-test, FSSG:

Frequency Scale for the Symptom of Gastroesophageal Reflux Disease, Max: maximum, Med: median, Min: minimum, PPI: proton pump inhibitor, SD: Standard deviation, VPZ: vonoprazan

Figures 


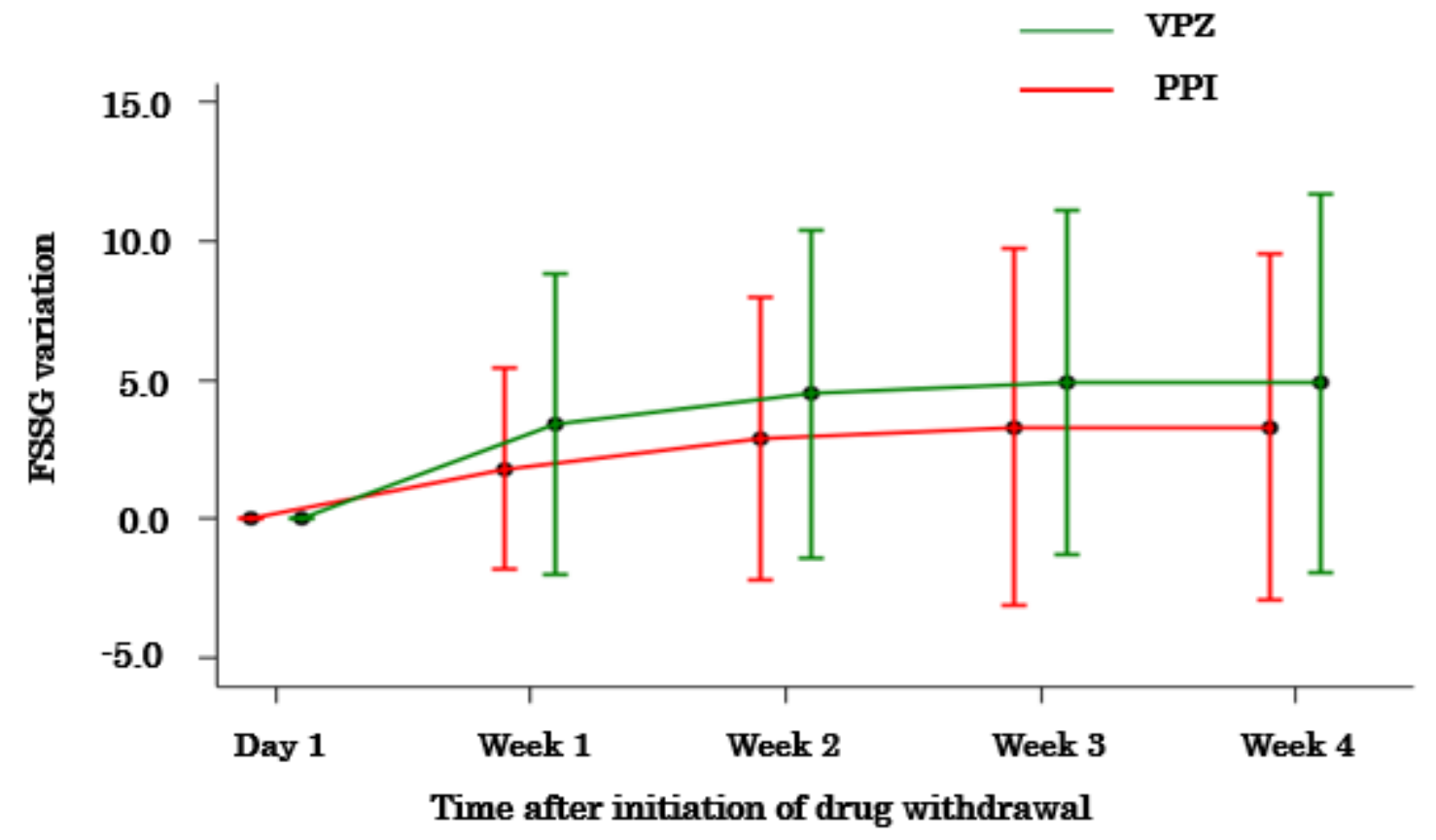

No. of patients: 46 to 47 in PPI dose group, 46 in VPZ dose group, PPI: proton pump inhibitor, VPZ: vonoprazan, Day 1: Initial day of drug withdrawal, Week 1 to Week 4: Measurement weeks after drug withdrawal

\section{Figure 1}

Change of variation of FSSG total score from Day 1

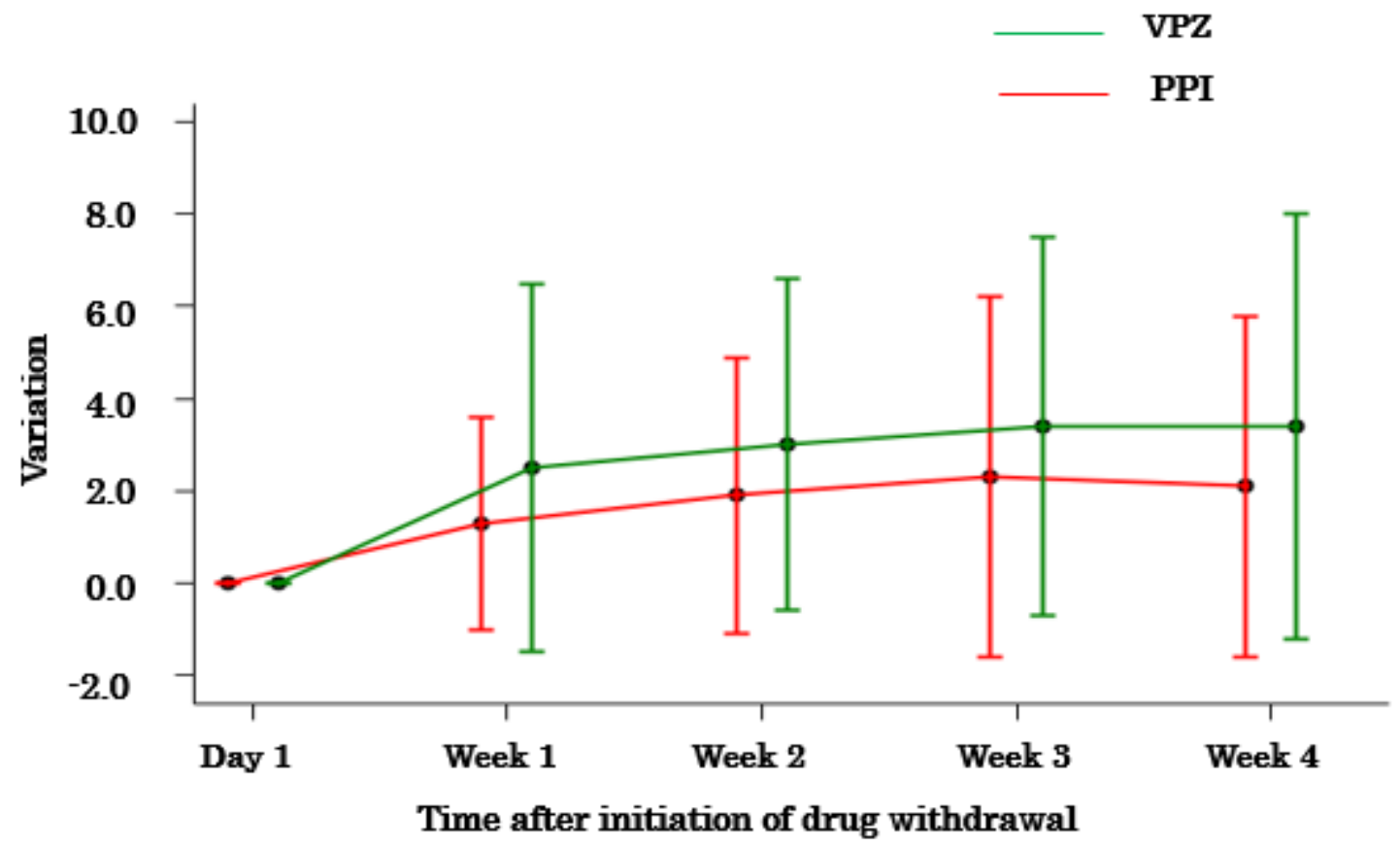

No. of patients: 46 in each dose group, PPI: proton pump inhibitor, VPZ: vonoprazan, Day 1: Initial day of drug withdrawal, Week 1 to Week 4 : Measurement weeks after drug withdrawal 
Figure 2

Change of variation of FSSG sub-score related to acid reflux from Day 1

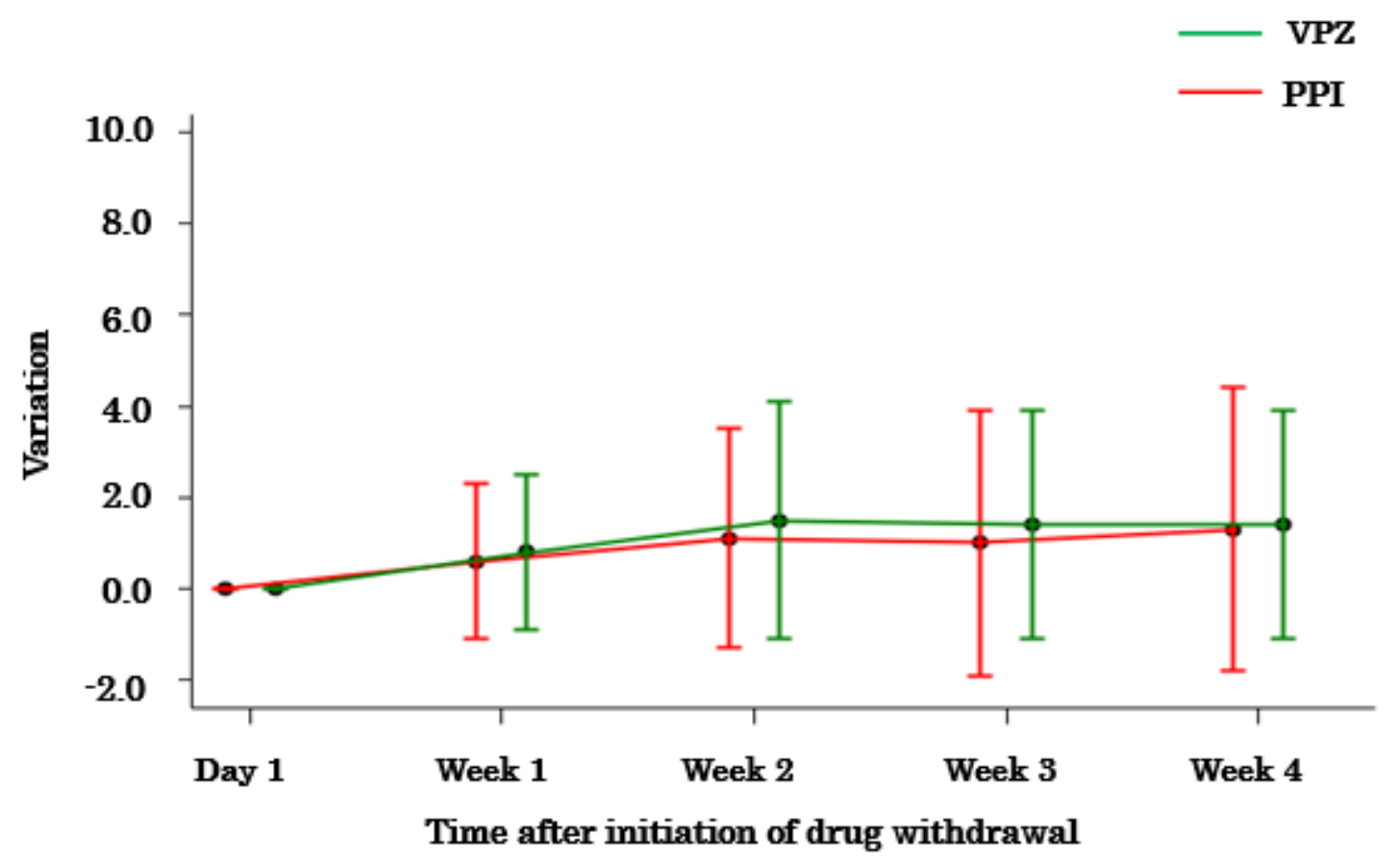

No. of patients: 46 to 47 in each dose group, PPI: proton pump inhibitor, VPZ: vonoprazan, Day 1: Initial day of drug withdrawal, Week 1 to Week 4: Measurement weeks after drug withdrawal

\section{Figure 3}

Change of variation of FSSG sub-score related to dysmotility from Day 1 


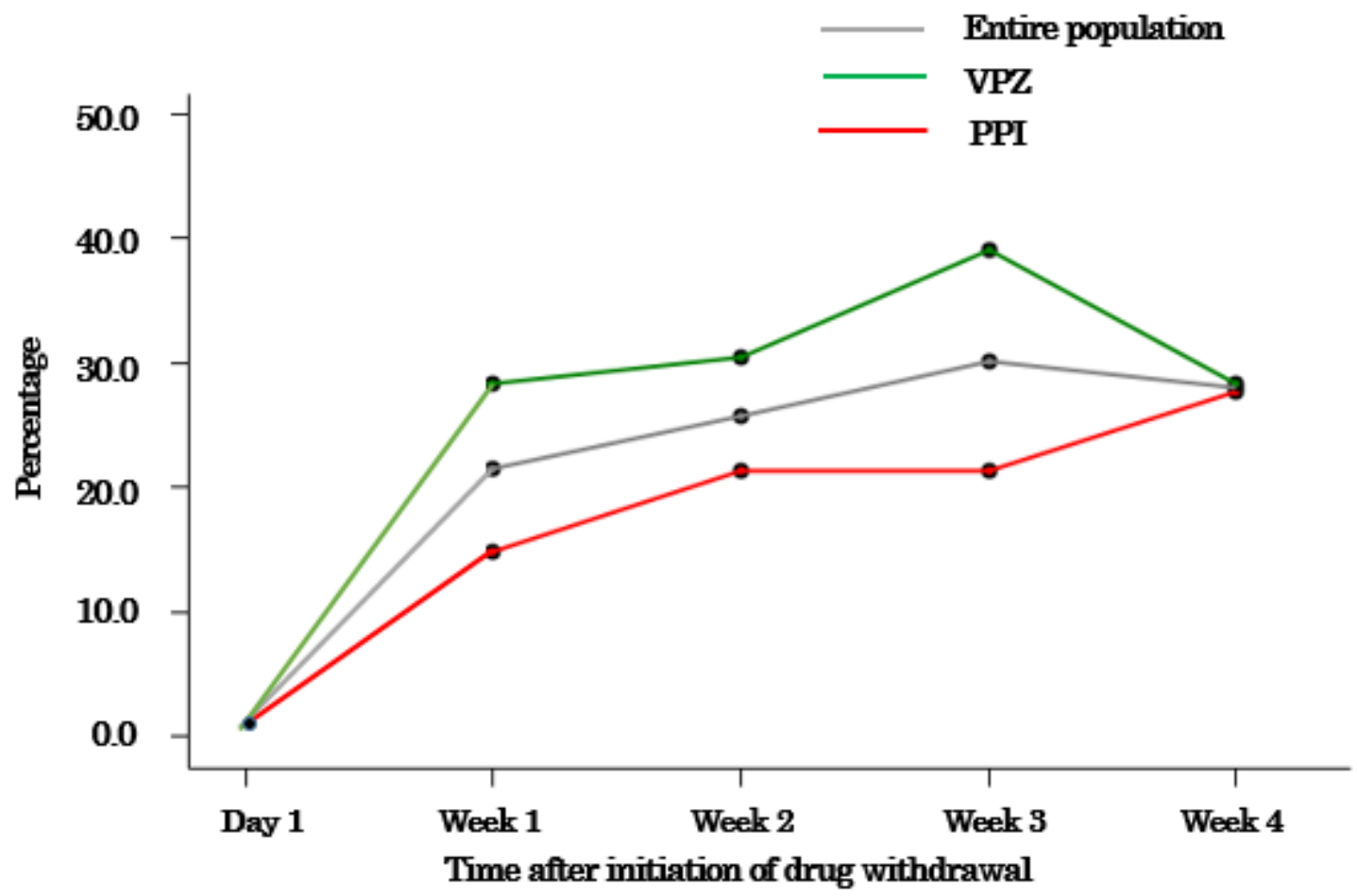

No. of patients: 46 to 47 in each dose group, PPI: proton pump inhibitor, VPZ: vonoprazan, Day 1: Initial day of drug withdrawal, Week 1 to Week 4: Measurement weeks after drug withdrawal, Statistical analvsis: paired t-test

\section{Figure 4}

Percentage of patients showing FSSG total score of 8 or higher at each time point

\section{Supplementary Files}

This is a list of supplementary files associated with this preprint. Click to download.

- EJMRupplementaryfile220114.docx 